\title{
DESENVOLVIMENTO E PRODUTIVIDADE DA MELANCIA EM FUNÇÃO DO MÉTODO DE CULTIVO
}

\author{
Graciela Maiara Dalastra ${ }^{1}$, Márcia de Moraes Echer ${ }^{1}$, Tiago Luan Hachmann ${ }^{1}$, Vandeir Francisco \\ Guimarães ${ }^{1}$, Mchele Hartmann Schmidt ${ }^{1}$, Félix Luis Corbari ${ }^{1}$ \\ ${ }^{1}$ Universidade Estadual do Oeste do Paraná, Brasil. E-mail: gradalastra@hotmail.com, mmecher@bol.com.br, \\ tiagohach@gmail.com, vandeirfg@yahoo.com.br, mialhartmann@hotmail.com, felixcorbari@gmail.com.br
}

\section{RESUMO}

Avaliou-se o desempenho da cultura da melancia cultivada por semeadura direta e por transplante de mudas produzidas em bandejas. Mudas produzidas em bandejas de volume de célula maior apresentaram melhor desenvolvimento e o método de semeadura direta foi o menos eficiente para a implantação da cultura da melancia.

Palavras-chave: Citrullus lanatus, Semeadura direta, Transplante de mudas

\section{DEVELOPMENT AND PRODUCTIVITY OF WATERMELON DEPENDING ON THE CULTIVATION METHOD}

\begin{abstract}
This paper evaluates the performance of the watermelon crop cultivated by direct seeding and transplanting seedlings from trays. When grown in larger cell volume trays, the seedlings show better development while the direct sowing method is less efficient for the cultivation of the watermelon crop.
\end{abstract}

Keywords: Citrullus lanatus, Direct sowing, Transplanting seedlings

\section{INTRODUÇÃO}

A melancia é uma cucurbitácea de grande importância econômica, sendo cultivada em vários países. De acordo com dados do Instituto Brasileiro de Geografia e Estatítica, em 2010, a produção nacional de melancia foi de cerca de 2.052.930 toneladas, com rendimento médio de 21.622 $\mathrm{Kg} \mathrm{ha}^{-1}$. No Brasil, as regiões Nordeste e Sul são as principais produtoras com 34,34\% e $24,64 \%$ do total da produção nacional dessa fruta (INSTITUTO BRASILEIRO DE GEOGRAFIA E ESTATÍTICA, 2010). 


\section{DESENVOLVIMENTO E PRODUTIVIDADE DA MELANCIA EM FUNÇÃO DO MÉTODO DE \\ CULTIVO}

A cultura é geralmente implantada por semeadura direta (REZENDE et al., 2010). No entanto este método proporciona campos de cultivo desuniformes, em função da má germinação ou do estresse gerado por temperaturas fora de faixas ótimas. A maior parte das cultivares tem ótima germinação entre 25 e $35^{\circ} \mathrm{C}$, quando a emergência ocorre em uma semana. À medida que a temperatura diminui, prolonga-se o período necessário para a germinação, expondo as plântulas, muito sensíveis, às condições adversas do campo por um período maior.

A implantação da cultura através da produção de mudas proporciona a vantagem de economizar sementes, o que é interessante principalmente no caso de sementes de alto custo, apresenta maior facilidade e economia nas irrigações e controle de pragas e doenças. Segundo Filgueira (2003) tal prática eleva a produtividade e a qualidade do produto final, além de reduzir o consumo de sementes.

A produção de mudas pode, também, ser um artifício utilizado pelo produtor para diminuir o tempo necessário para colheita, permitindo melhor utilização da área. Conforme Rezende et al. (2010) a época de plantio mais favorável para a melancia na região sul do Brasil é de outubro a fevereiro, quando as temperaturas variam de $18^{\circ} \mathrm{C}$ a $25^{\circ} \mathrm{C}$. Assim, a formação de mudas em condições de ambiente protegido pode ser realizada antecipadamente, e quando as condições ambientais forem favoráveis o plantio é realizado no campo.

A produção de mudas de hortaliças constitui uma das etapas mais importantes do sistema produtivo, influenciando diretamente o desempenho final das plantas (GUIMARÃES et al., 2007). Mudas de formação inadequada debilitam e afetam todo o desenvolvimento da cultura, aumentando seu ciclo e acarretando em perdas na produção, pois existe uma relação direta entre mudas de boa qualidade e sua produção no campo (ECHER et al., 2007).

Para a obtenção de mudas de alta qualidade, Gonçalves (1996) menciona que é importante escolher sementes e substratos de boa qualidade. Além da escolha criteriosa do local de produção dessas mudas, também deve-se ter cuidado com a nutrição mineral, os tratos fitossanitários, o controle sanitário do local e o manejo adequado da irrigação.

O tamanho do recipiente e o tipo do substrato são os principais aspectos a serem estudados para garantir a produção de mudas de boa qualidade. O primeiro fator afeta diretamente o volume disponível para o desenvolvimento das raízes, permitindo o crescimento sem que haja restrições 
significativas do sistema radicular, e o segundo é responsável pelo fornecimento de nutrientes e pela capacidade de retenção de água, que afeta intensamente a qualidade das mudas (JESUS et al., 1987; LATIMER, 1991). Além de que a escolha do substrato é limitada pelo seu custo e sua qualidade (RODRIGUES et al., 2010).

$\mathrm{Na}$ literatura são encontrados diversos estudos que relatam o efeito do volume do recipiente no desenvolvimento de mudas. Echer et al. (2007), ao estudar o efeito de dois tamanhos de célula na produção de mudas de beterraba, concluíram que bandejas com 128 células proporcionaram mudas de melhor qualidade, quando comparadas às mudas produzidas em bandejas de 200 células. Rodrigues et al. (2010), ao testar bandejas de 72, 128 e 200 células, na produção de mudas de tomate, verificaram que a utilização de bandejas de 72 células é a melhor opção para formação das mudas de tomateiro. Marques et al. (2003), ao avaliar o efeito de três tipos de bandejas sobre a produção de mudas de alface, concluíram que as melhores mudas foram produzidas em bandejas de 128 células e que as mudas produzidas em bandejas de 288 células foram as que apresentaram os piores desempenhos.
Segundo Taveira (1995), as principais funções dos recipientes para a produção de mudas são: proporcionar um meio para suportar e nutrir as plantas, proteger as raízes dos danos mecânicos e da dessecação, dar uma conformação vantajosa para as raízes das mudas e maximizar a sobrevivência no campo, pois o sistema radicular não é danificado e permanece em contato íntimo com o substrato.

O presente trabalho teve como objetivo avaliar a influência das semeaduras direta e indireta como métodos de implantação, no desenvolvimento e produtividade da cultura da melancia.

\section{MATERIAL E MÉTODOS}

O trabalho foi conduzido em duas etapas, no período de setembro a dezembro de 2005. A primeira etapa foi a produção de mudas em bandejas de poliestireno expandido, em casa de vegetação na área de horticultura e cultivo protegido. A segunda etapa foi composta pela condução das plantas em condições de campo, na Fazenda Experimental. As áreas pertencem à Unioeste, Campus de Marechal Cândido Rondon, PR. O clima, classificado segundo Koppen, é do tipo Cfa, subtropical, com média anual de precipitação de $1700 \mathrm{~mm}$, 
mantendo a média anual de temperatura entre 22 e $23^{\circ} \mathrm{C}$ (CAVIGLIONE et al., 2001). O solo é classificado como Latossolo Vermelho eutroférrico de textura argilosa (EMBRAPA, 2006).

O solo em que foi instalado o experimento apresentou, na camada de 0-20 $\mathrm{cm}$ de profundidade, as seguintes características: $\mathrm{pH}\left(\mathrm{CaCl}_{2}\right)=6,01 \mathrm{mg} \mathrm{dm}^{-3}$; $\mathrm{Ca}^{2+}=6,69 ; \mathrm{Mg}^{2+}=3,7 ; \mathrm{K}=0,92 ; \mathrm{Al}^{3+}=0 ;$ $\mathrm{H}+\mathrm{Al}=2,74 ; \quad \mathrm{CTC}=14,05$, expressos em $\mathrm{cmol}_{\mathrm{c}} \mathrm{dm}^{-3} ; \mathrm{V}(\%)=80,5 ; \mathrm{P}=71,1 \mathrm{mg} \mathrm{dm}^{-3}$ e matéria orgânica $=20,51 \mathrm{~g} \mathrm{dm}^{-3}$.

O delineamento experimental utilizado foi o de blocos ao acaso, com quatro repetições. $\mathrm{Na}$ etapa relativa à produção de mudas, realizada em casa de vegetação, foram utilizadas bandejas de poliestireno expandido de 72 células com $121,2 \mathrm{~cm}^{3}$ e 128 células com $34,6 \mathrm{~cm}^{3}$. A semeadura foi feita de forma manual, colocando-se o número de sementes de acordo com o tratamento (uma ou duas sementes). Os tratamentos foram relativos ao método de implantação da cultura da melancia (Híbrido Eureca), sendo: T1 produção de mudas em bandejas de 128 células $\left(34,6 \mathrm{~cm}^{3}\right)$, com uma muda por célula; T2 - produção de mudas em bandejas de 72 células $\left(121,2 \mathrm{~cm}^{3}\right)$, com uma muda por célula; T3 - produção de mudas em bandejas de 72 células $\left(121,2 \mathrm{~cm}^{3}\right)$, com uma muda por célula até a formação do torrão; T4 - produção de mudas em bandejas de 72 células $\left(121,2 \mathrm{~cm}^{3}\right)$, com duas mudas por célula; e T5 - semeadura direta no campo.

A área experimental foi preparada de forma convencional, com as operações de aração, gradagem e marcação das covas. A adubação de base utilizada foi de $10 \mathrm{t} \mathrm{ha}^{-1}$ de esterco de curral e $750 \mathrm{~kg} \mathrm{ha}^{-1}$ do adubo formulado 04-14-08. Foram instaladas aleatoriamente vinte parcelas experimentais, constituídas por 8 plantas, espaçadas $2 \mathrm{~m}$ entre plantas e $2 \mathrm{~m}$ entre linhas. Cada parcela ocupou uma área de $16 \mathrm{~m}^{2}$, o que resultou em uma área experimental de 320 $\mathrm{m}^{2}$.

As mudas referentes aos tratamentos T1, T2 e T4 foram transplantadas para campo aos 30 dias após a semeadura (DAS), enquanto as mudas do tratamento T3 foram transplantadas aos 37 DAS. Quanto à semeadura direta no campo (T5), esta foi realizada no mesmo dia da semeadura nas bandejas, em 06 de Setembro de 2005, colocando-se cinco sementes por cova. Após a emergência as plântulas foram desbastadas, deixando-se apenas duas plantas por cova, totalizando 16 plantas por parcela. Posterior ao transplante das mudas 
para o campo a área experimental foi irrigada uma vez ao dia, através de um sistema de irrigação por aspersão convencional.

A adubação de cobertura, com nitrogênio e potássio, foi realizada aos 30 e aos 60 DAS. Os tratos culturais, como capinas e controle de pragas e doenças, foram realizados no decorrer do ciclo da cultura, à medida que se tornavam necessários.

No momento do transplante foram realizadas avaliações de dez plantas de cada tratamento, sendo as variáveis avaliadas: a altura das plantas $(\mathrm{cm})$; diâmetro do colmo (mm); número de folhas; área foliar $\left(\mathrm{cm}^{2}\right)$; volume das raízes $\left(\mathrm{cm}^{3}\right)$; massa seca da parte aérea $(\mathrm{g})$; massa seca das raízes $(\mathrm{g})$. A altura das plantas foi determinada com régua graduada, medindo a distância entre o colo e o ápice da planta. $\mathrm{O}$ diâmetro do colmo foi determinado com auxílio de um paquímetro digital a $3 \mathrm{~cm}$ do colo da planta. $\mathrm{O}$ número de folhas foi obtido considerando as folhas cotiledonares. As variáveis relativas à massa seca dos órgãos foram obtidas após secagem em estufa de circulação forçada de ar a 65 $\pm 5^{\circ} \mathrm{C}$ por 48 horas e pesagem em balança de precisão.

$\begin{array}{rrr} & \text { A área foliar foi determinada } \\ \text { através de } & \text { amostragens, } & \text { seguindo }\end{array}$ metodologia de Benicasa (1988). Para tal, após a separação das folhas, foram retirados 10 discos foliares com auxílio de furador cilíndrico de metal de $1,05 \mathrm{~cm}$ de diâmetro, totalizando uma área de $1,64 \mathrm{~cm}^{2}$, que foi considerada a área foliar da amostra $\left(\mathrm{AF}_{\text {amostra }}\right)$. Em seguida, determinou-se a massa desta amostra ( $\left.\mathrm{MS}_{\mathrm{amostra}}\right)$ e a massa do total de folhas (MSF). A área foliar total (AF) foi obtida através da seguinte equação: $\mathrm{AF}=\left[\left(\mathrm{AF}_{\text {amostra }} \mathrm{x} \mathrm{MF}\right) / \mathrm{M}_{\mathrm{amostra}}\right]$.

$\mathrm{O}$ volume de raízes foi determinado após lavagem das mesmas em água corrente com auxílio de uma peneira e secagem à sombra por uma hora. As raízes foram mergulhadas em uma proveta contendo um volume conhecido de água, sendo o volume radicular obtido pelo volume de deslocamento do líquido.

Foram avaliados durante o ciclo da cultura: número de frutos por planta; massa de frutos por planta $(\mathrm{Kg})$; produtividade $(\mathrm{t}$ $\mathrm{ha}^{-1}$ ) e teor de sólidos solúveis ( ${ }^{\mathrm{o}} \mathrm{Brix}$ ).

A colheita das unidades experimentais foi realizada em duas etapas, aos 101 e 108 dias após semeadura (DAS), quando as plantas apresentaram a maioria dos frutos com a gavinha, anterior ao fruto, seca. Os frutos foram pesados e classificados em "comerciais" (frutos acima de $6 \mathrm{~kg}$ e não deformados) e "não comerciais" (frutos 


\section{DESENVOLVIMENTO E PRODUTIVIDADE DA MELANCIA EM FUNÇÃO DO MÉTODO DE \\ CULTIVO}

abaixo de 6 kg) (RODRIGUES de MIRANDA, et al., 2005), sendo posteriormente mensurados o diâmetro e comprimento desses frutos. A produtividade foi obtida extrapolando-se a massa de frutos da parcela para a área de 1 ha.

Para a determinação de sólidos solúveis totais foi utilizado um refratômetro portátil RT-30ATC, sendo que as amostras foram retiradas da parte central dos frutos.

Depois de tabulados, os dados foram submetidos à análise de variância e as médias dos tratamentos comparadas pelo teste de Tukey a $5 \%$ de probabilidade.

\section{RESULTADOS E DISCUSSÃO}

Os resultados (Tabelas 1 e 2 ) demonstram o efeito do volume das células das bandejas no desenvolvimento de plantas de melancia. No momento em que as mudas foram avaliadas (30 DAS), os tratamentos 2 e 4 apresentaram os melhores resultados para a maioria dos parâmetros avaliados, diferindo apenas para diâmetro de caule e área foliar, onde o tratamento 2 apresentouse superior ao tratamento 4 , já que não havia competição por espaço e substrato com mais de uma plântula neste tratamento.

Comparando o tratamento 2 com o tratamento 5 , observa-se que para todas as variáveis, exceto para o número de folhas, quando as mudas foram produzidas em bandejas de 72 células (T2), estas apresentaram maior altura de plantas, diâmetro de caule, área foliar e volume de raízes em relação a semeadura direta (T5), confirmando a importância de se realizar a prática da produção de mudas, concordando com os resultados de Marques et al. (2003), ou seja, que bandejas com células de maior volume possibilitam a formação de melhores mudas, com maior vigor e proporcionam melhor desenvolvimento das plantas após o transplante.

O tratamento onde as mudas foram avaliadas 37 DAS demonstrou-se superior em todos os parâmetros avaliados, pelo fato destas mudas terem permanecido sete dias a mais nas bandejas que as dos tratamentos 1 , 2 e 4 (Tabela 2).

Para os dados de massa seca (Tabela 2), pode-se observar maiores valores de massa para o tratamento 3, que permaneceu por mais dias nas bandejas. Aos 30 DAS os tratamentos 2 e 4 apresentaram também bons resultados. Esse resultado é atribuído novamente ao maior volume do recipiente, que propicia maior disponibilidade de água, luz e nutrientes para as mudas em desenvolvimento. 
Tabela 1. Altura de plantas (AP), número de folhas (NF), diâmetro do caule (DC), área foliar (AF) e volume de raízes (VR) de mudas de melancia (híbrido Eureca), aos 30 dias após a semeadura (DAS), em função de diferentes métodos de implantação da cultura, Marechal Cândido Rondon, PR. 2005.

\begin{tabular}{|c|c|c|c|c|c|}
\hline \multirow{2}{*}{ Tratamentos } & $\mathbf{A P}$ & \multirow{2}{*}{ NF } & DC & $\mathbf{A F}$ & VR \\
\hline & $-\mathrm{cm}-$ & & -mm- & $-\mathrm{cm}^{2}-$ & $-\mathrm{cm}^{3}-$ \\
\hline 1 & $3,30 \mathrm{c}$ & $4,43 \mathrm{~b}$ & $4,10 \mathrm{c}$ & $20,07 \mathrm{~b}$ & $5,63 \mathrm{~b}$ \\
\hline 2 & $3,94 \mathrm{~b}$ & $4,85 \mathrm{~b}$ & $4,90 \mathrm{~b}$ & 35,18 a & $5,63 \mathrm{~b}$ \\
\hline $3 *$ & $7,00 \mathrm{a}$ & $6,55 \mathrm{a}$ & $5,63 \mathrm{a}$ & $35,72 \mathrm{a}$ & $11,00 \mathrm{a}$ \\
\hline $4 * *$ & $4,23 \mathrm{~b}$ & $4,31 \mathrm{~b}$ & $4,17 \mathrm{c}$ & $25,24 \mathrm{~b}$ & $5,25 \mathrm{~b}$ \\
\hline 5 & $3,30 \mathrm{c}$ & $4,20 \mathrm{~b}$ & $3,06 \mathrm{~d}$ & $8,20 \mathrm{c}$ & $1,65 \mathrm{c}$ \\
\hline Média & 4,35 & 4,87 & 4,37 & 24,88 & 5,83 \\
\hline CV $(\%)$ & 5,69 & 7,58 & 4,88 & 9,45 & 15,89 \\
\hline
\end{tabular}

*Avaliação realizada aos 37 DAS.

**Valores referentes à média de duas mudas.

Letras iguais na coluna não diferem estatisticamente pelo teste de Tukey $(\mathrm{P}<0,05)$.

Tratamentos: (1) - Bandeja de 128 células; (2) - Bandeja de 72 células com uma muda por célula; (3) - Bandeja de 72 células com uma muda por célula, com torrão formado; (4) - Bandeja de 72 células com duas mudas por células; (5) - Semeadura direta no campo

Tabela 2. Massa seca de folhas (MSF), massa seca de caule (MSC), massa seca de raízes (MSR), massa seca da parte aérea (MSPA), massa seca total (MST) e razão raiz:parte aérea (RRPA) de mudas de melancia (híbrido Eureca), aos 30 dias após a semeadura (DAS), em função de diferentes métodos de implantação da cultura, Marechal Cândido Rondon, PR. 2005.

\begin{tabular}{|c|c|c|c|c|c|c|}
\hline \multirow{2}{*}{ Tratamentos } & MSF & MSC & MSR & MSPA & MST & \multirow{2}{*}{ RRPA } \\
\hline & \multicolumn{5}{|c|}{ 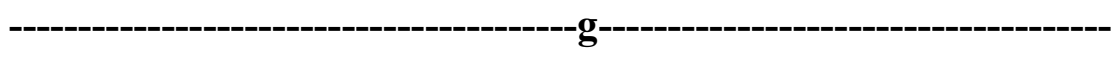 } & \\
\hline 1 & $0,85 \mathrm{c}$ & $0,39 \mathrm{~cd}$ & $0,21 \mathrm{~b}$ & $1,24 \mathrm{c}$ & $1,45 \mathrm{c}$ & $0,17 \mathrm{a}$ \\
\hline 2 & $1,51 \mathrm{~b}$ & $0,57 \mathrm{bc}$ & $0,21 \mathrm{~b}$ & $2,08 \mathrm{~b}$ & $2,29 \mathrm{~b}$ & $0,10 \mathrm{~b}$ \\
\hline $3 *$ & $3,78 \mathrm{a}$ & $2,03 \mathrm{a}$ & $0,54 \mathrm{a}$ & $5,81 \mathrm{a}$ & $6,35 \mathrm{a}$ & $0,09 \mathrm{~b}$ \\
\hline 4 & $1,72 \mathrm{~b}$ & $0,79 \mathrm{~b}$ & $0,21 \mathrm{~b}$ & $2,51 \mathrm{~b}$ & $2,72 \mathrm{~b}$ & $0,08 \mathrm{~b}$ \\
\hline 5 & $0,45 \mathrm{c}$ & $0,13 \mathrm{~d}$ & $0,05 \mathrm{c}$ & $0,58 \mathrm{c}$ & $0,63 \mathrm{c}$ & $0,08 \mathrm{~b}$ \\
\hline Média & 1,66 & 0,78 & 0,24 & 2,44 & 2,69 & 0,10 \\
\hline CV (\%) & 13,63 & 15,91 & 11,75 & 14,16 & 13,67 & 15,94 \\
\hline
\end{tabular}

*Avaliação realizada aos 37 DAS.

Letras iguais na coluna não diferem estatisticamente pelo teste de Tukey $(\mathrm{P}<0,05)$.

Tratamentos: (1) - Bandeja de 128 células; (2) - Bandeja de 72 células com uma muda por célula; (3) - Bandeja de 72 células com uma muda por célula, com torrão formado; (4) - Bandeja de 72 células com duas mudas por células; (5) - Semeadura direta no campo 


\section{DESENVOLVIMENTO E PRODUTIVIDADE DA MELANCIA EM FUNÇÃO DO MÉTODO DE

Observa-se (Tabela 2) que quando as mudas foram produzidas em bandejas de 128 células (T1), seu comportamento foi semelhante ao tratamento de semeadura direta (T5), para a maioria das variáveis analisadas. Isso acontece devido ao volume reduzido no recipiente, ocorrendo maior concentração de raízes, o que aumenta a demanda evapotranspiratória, necessitando assim de irrigações mais frequentes para $o$ suprimento de água pelas mudas. No entanto, irrigações frequentes podem ocasionar a lixiviação dos nutrientes contidos no substrato, levando a uma deficiência nutricional que acarretará em desenvolvimento insatisfatório das mudas (SALVADOR et al. 2001).

No que diz respeito à relação raiz/parte aérea os resultados demonstram maior valor no tratamento 1, provavelmente devido ao menor volume de célula ocupado pelas raízes. Essa relação fornece um índice de equilíbrio entre a partição de fotoassimilados entre essas duas partes da planta. Pereira \& Martinez (1999) afirmam que mudas produzidas em volumes de células maiores são mais vigorosas, apresentando uma relação parte aérea/raiz mais equilibrada, o que proporciona melhor desempenho no campo.
Em trabalhos semelhantes foram observadas diferenças no volume de substrato influenciando o desenvolvimento das mudas de beterraba (ECHER et al., 2000), alface (SILVA et al., 2000), brócolis (SILVA et al., 2000), berinjela (BARNABÉ et al., 1994a) e pimentão (BARNABÉ et al., 1994b). Em pepino, Seabra Junior et al. (2004), ao estudar o comportamento de diferentes recipientes na produção de mudas, utilizando bandejas de poliestireno expandido com volumes de $34,6 \mathrm{~cm}^{3}$ e 121,2 $\mathrm{cm}^{3}$, verificaram que quanto maior o volume das células, maior o peso total, peso de matéria seca da parte aérea, das raízes e também maior área foliar das mudas.

Na Flórida, Maynard et al. (1996) testando recipientes de diferentes volumes $\left(7 ; 22 ; 25 ; 36 ; 50 ; 70\right.$ e $\left.100 \mathrm{~cm}^{3}\right)$ na produção de mudas de melão, observaram resultados significativos comparando os diferentes volumes de recipientes. O número de frutos totais e a produtividade total aumentaram em função do aumento do volume de células.

Seabra Junior et al. (2004), estudando a produção de mudas de pepino com diferentes volumes de substrato e com diferentes idades no transplante, observaram que quanto mais velha e maior a muda (diâmetro, altura, número de folhas, área 
foliar, massa fresca e seca da parte aérea), menor a produção total de frutos por planta bem como a produção comercial. Assim, mudas maiores foram as de pior qualidade.

Analisando os dados (Tabelas $1 \mathrm{e}$ 2), verifica-se que o tratamento 5 proporcionou menor desenvolvimento das plantas de melancia comparado com os demais tratamentos, este fato, já era esperado, pois estas plântulas estão mais suscetíveis aos intempéries climáticos, principalmente pela temperatura e pela maior resistência do solo comparado ao substrato para o desenvolvimento radicular dessas plântulas. Com relação à produção total de frutos, a semeadura direta proporcionou aumento de $13,5 \%$ e quanto ao formato e qualidade dos frutos não se verificou efeito dos recipientes na formação das mudas.

\section{Analisando os resultados referentes} às variáveis avaliadas no momento da colheita, verifica-se que houve diferença estatística entre os tratamentos apenas para o número de frutos por planta (Tabela 3) e número de frutos não comerciais (Tabela 4).

As plantas provenientes da semeadura direta no campo (tratamento 5) resultaram em menor número de frutos, provavelmente devido ao maior estresse sofrido por estas plantas desde da geminação das sementes.

Tabela 3. Número de frutos por planta (NFP), diâmetro de frutos comerciais (DFC), comprimento de frutos comerciais (CFC), diâmetro de frutos não comerciais (DFNC), e comprimento de frutos não comerciais (CFNC) de mudas de melancia (híbrido Eureca), em função de diferentes métodos de implantação da cultura, Marechal Cândido Rondon, PR. 2005.

\begin{tabular}{|c|c|c|c|c|c|}
\hline \multirow{2}{*}{ TRAT } & \multirow{2}{*}{ NFP } & DFC & CFC & DFNC & CFNC \\
\hline & & \multicolumn{4}{|c|}{--------------------------------------cm---------------------------------------- } \\
\hline 1 & $1,79 \mathrm{a}$ & $25,11 \mathrm{a}$ & $26,80 \mathrm{a}$ & $18,74 \mathrm{a}$ & $19,90 \mathrm{a}$ \\
\hline 2 & $1,20 \mathrm{~b}$ & $24,71 \mathrm{a}$ & $26,46 \mathrm{a}$ & $20,72 \mathrm{a}$ & $21,87 \mathrm{a}$ \\
\hline 3 & $1,41 \mathrm{ab}$ & $24,77 \mathrm{a}$ & $27,06 \mathrm{a}$ & $20,25 \mathrm{a}$ & $21,40 \mathrm{a}$ \\
\hline 4 & $1,37 \mathrm{ab}$ & $24,21 \mathrm{a}$ & $25,70 \mathrm{a}$ & $20,38 \mathrm{a}$ & $21,02 \mathrm{a}$ \\
\hline 5 & $1,03 \mathrm{~b}$ & $24,81 \mathrm{a}$ & $26,96 \mathrm{a}$ & $18,36 \mathrm{a}$ & $19,90 \mathrm{a}$ \\
\hline Média & 1,36 & 24,72 & 26,60 & 19,70 & 20,82 \\
\hline CV (\%) & 16,14 & 4,04 & 5,05 & 10,70 & 10,85 \\
\hline
\end{tabular}

Letras iguais na coluna não diferem estatisticamente pelo teste de Tukey $(\mathrm{P}<0,05)$.

Tratamentos: (1) - Bandeja de 128 células; (2) - Bandeja de 72 células com uma muda por célula; (3) - Bandeja de 72 células com uma muda por célula, com torrão formado; (4) - Bandeja de 72 células com duas mudas por células; (5) - Semeadura direta no campo. 
Tabela 4. Número de frutos comerciais por parcela (NFC), número de frutos não comerciais por parcela (NFNC), massa de frutos comerciais (MFC), massa frutos não comerciais (MFNC), produção comercial (PC) produção total (PT), sólidos solúveis (SS) de frutos de melancia (híbrido Eureca), aos 101 dias após a semeadura (DAS), em função de diferentes métodos de implantação da cultura, Marechal Cândido Rondon, PR. 2005.

\begin{tabular}{|c|c|c|c|c|c|c|c|}
\hline \multirow[b]{2}{*}{ TRAT } & \multirow[b]{2}{*}{ NFC } & \multirow[b]{2}{*}{ NFNC } & MFC & MFNC & $\mathbf{P C}$ & PT & SS \\
\hline & & & \multicolumn{2}{|c|}{--------------kg------------- } & \multicolumn{2}{|c|}{-------ton ha ${ }^{-1}-------$} & $-{ }^{\circ}$ Brix- \\
\hline 1 & $5,75 \mathrm{a}$ & $8,50 \mathrm{a}$ & $8,29 \mathrm{a}$ & $3,80 \mathrm{a}$ & $29,93 \mathrm{a}$ & $81,16 \mathrm{a}$ & $11,55 \mathrm{a}$ \\
\hline 2 & $6,25 \mathrm{a}$ & $3,25 \mathrm{~b}$ & $8,07 \mathrm{a}$ & $3,57 \mathrm{a}$ & $31,46 \mathrm{a}$ & $61,86 \mathrm{a}$ & $11,00 \mathrm{a}$ \\
\hline $3 *$ & $4,75 \mathrm{a}$ & $6,25 \mathrm{ab}$ & $7,95 \mathrm{a}$ & $4,63 \mathrm{a}$ & $23,42 \mathrm{a}$ & $66,02 \mathrm{a}$ & $9,76 \mathrm{a}$ \\
\hline 4 & $6,25 \mathrm{a}$ & $4,50 \mathrm{ab}$ & $7,53 \mathrm{a}$ & $4,74 \mathrm{a}$ & $29,58 \mathrm{a}$ & $68,41 \mathrm{a}$ & $10,80 \mathrm{a}$ \\
\hline 5 & $6,00 \mathrm{a}$ & $2,25 \mathrm{~b}$ & $8,29 a$ & $3,86 \mathrm{a}$ & $31,41 \mathrm{a}$ & $59,41 \mathrm{a}$ & $10,38 \mathrm{a}$ \\
\hline Média & 5,80 & 4,95 & 8,03 & 4,12 & 29,16 & 67,37 & 10,70 \\
\hline $\mathrm{CV}(\%)$ & 25,86 & 43,52 & 10,52 & 24,73 & 30,11 & 19,33 & 11,17 \\
\hline
\end{tabular}

*Avaliação realizada aos 108 DAS.

Letras iguais na coluna não diferem estatisticamente pelo teste de Tukey $(\mathrm{P}<0,05)$.

Tratamentos: (1) - Bandeja de 128 células; (2) - Bandeja de 72 células com uma muda por célula; (3) - Bandeja de 72 células com uma muda por célula, com torrão formado; (4) - Bandeja de 72 células com duas mudas por células; (5) - Semeadura direta no campo.

Observa-se (Tabela 4) que houve diferença significativa entre os tratamentos apenas para o parâmetro número de frutos não comerciais por parcela, onde os tratamentos 2 e 5 proporcionaram o menor número de frutos não comerciais garantindo desta forma maior renda ao produtor. Seabra Junior et al. (2004) observaram acréscimo de $25 \%$ na produção comercial de pepino quando utilizaram mudas produzidas em volume maior de substrato.

As plantas obtidas de bandeja, independente do volume de substrato, apresentaram maior desenvolvimento vegetativo que as plantas obtidas da semeadura direta, resultando em um número total de frutos maior, ocasionando aumento da produção total. No entanto, esses frutos apresentaram menor massa, ficando em sua maioria abaixo de $6 \mathrm{Kg}$ não sendo classificados como fruto comercial.

$\mathrm{O}$ tratamento 5 apresentou menor número de frutos por planta, no entanto a maioria dos frutos atingiu mais de $6 \mathrm{Kg}$, aumentando assim a produção de frutos comerciais.

O teor de sólidos solúveis não diferiu estatisticamente entre os tratamentos, atingindo valor médio de $10,70^{\circ}$ Brix, ficando dentro do valor indicado para a 
cultivar, que é em torno de $12^{\circ}$ Brix. Para esta variável, apesar de não se observar diferença estatística, o tratamento 3 foi o que resultou em frutos com menor valor de ${ }^{\circ}$ Brix, isso pode ser em decorrência do maior tempo em que a planta permaneceu na bandeja, reduzindo o tempo de permanência no campo consequentemente para uma possível translocação de fotoassimilados da parte aérea para os frutos, tendo em vista que o tratamento 3 foi o que apresentou maiores valores de massa seca da parte aérea, no momento da avaliação das mudas (Tabela 2).

\section{CONCLUSÕES}

O tamanho das células das bandejas influenciou na formação de mudas de melancia, sendo que bandeja de 72 células com as mudas transplantadas 37 dias após a semeadura é a melhor opção para a formação de mudas de melancia. A semeadura direta não é a forma mais adequada para a implantação da cultura da melancia.

\section{REFERÊNCIAS}

INSTITUTO BRASILEIRO DE GEOGRAFIA E ESTATÍTICA. 2010. Sistema IBGE de Recuperação Automática. Banco de dados agregados. Brasília: IBGE. On line. Disponível em: $<$ http://www.sidra.ibge.gov.br/tabela/protabl .asp> Acesso em: 01 jul. de 2013.
BARNABÉ, F.A.; GIORGETTI, J.R.; GOTO, R. 1994a. Influência de três tipos de bandejas, para a produção de mudas de berinjela. Horticultura Brasileira, Brasília, v.18, p.71.

BARNABÉ, F.A.; GIORGETTI, J.R.; GOTO, R. 1994b. Influência de três tipos de bandejas, para a produção de mudas de pimentão. Horticultura Brasileira, Brasília, v.18, p.71.

BENICASA, M.M.P. 1988. Análise de crescimento de plantas: noções básicas. Jaboticabal. FUNEP, 42p.

CAVIGLIONE， J.H.; KIHL， L.R.B.; CARAMORI, P.H.; OLIVEIRA, D. 2000. Cartas climáticas do Paraná. Londrina: IAPAR. On line. Disponível em: http://www.iapar.br/modules/conteudo/conte udo.php? conteudo=677. Acesso em: 5 ago. 2013.

ECHER, M.M.; ARANDA, A.N.; BORTOLAZZO, E.D.; BRAGA, J.S.; TESSARIOLI NETO, J. 2000. Efeito de três substratos e dois recipientes na produção de mudas de beterraba. Horticultura Brasileira, Brasília, v.18, p.509-510.

ECHER, M.M.; GUIMARÃES, V.F.; ARANDA, A.N.; BORTOLAZZO, E.D.; BRAGA, J.S. 2007. Avaliação de mudas de beterraba em função do substrato e do tipo de bandeja. Ciências Agrárias, Londrina, v.28, p. 45-50.

EMBRAPA, Centro Nacional de Pesquisa em Solos. 2006. Sistema brasileiro de classificação de solos. Rio de Janeiro: Embrapa-Solos. 306p.

GONÇALVES, F. C.; MENEZES, J. B.; ALVES, R. E. 1996. Vida útil pós-colheita de melão 'Piel de Sapo' armazenado em condições ambiente. Horticultura Brasileira, Brasília, v.14, p. 49-52.

GUIMARÃES, V.F.; ECHER, M.M.; MINAMI, K. 2002. Métodos de produção de 
mudas, distribuição de matéria seca produtividade de plântulas de beterraba. Horticultura Brasileira, Brasília, v.20, p.505-509.

JESUS, R.M.; MENANDRO, M.S.; BATISTA, J.L.F.; COUTO, H.T. 1987. Efeito do tamanho do recipiente, tipo de substrato e sombreamento na produção de mudas de louro (Cordia trichotoma (Vell) Arrab.) e Gonçalo-Alves (Astronium fraxinifolium Schott). Instituto de Pesquisas e Estudos Florestais, Piracicaba, n.37, p.13-19.

LATIMER, J.G. 1991.Container size and shape influence growtth and landscape performance of marigold seedling. HortScience, Alexandria, v.26, n.2, p.124126.

MARQUES, P.A.A.; BALDOTTO, P.V.; SANTOS, A.C.P.; OLIVEIRA, L. 2003. Qualidade de mudas de alface formadas em bandejas de isopor com diferentes números de células. Horticultura Brasileira, Brasília, v. 21, n. 4, p. 649-651.

MAYNARD, E.T.; VAVRINA, C.S.; SCOTT, W.D. 1996. Containerized muskmelon transplants: cell volume effects on pretransplant development and subsequent yield. HortScience, Alexandria, v.31, p.58-61.

MINAMI, K. 1995. Produção de mudas de hortaliças de alta qualidade em horticultura. São Paulo. T. A. Queiroz. $128 \mathrm{p}$.

PEREIRA, P.R.G., MARTINEZ, H.E.P. 1999. Produção de mudas para o cultivo de hortaliças em solo e hidroponia. Informe Agropecuário, Belo Horizonte, v.20, n.200/201, p.24-31.

PUIATTI, M., SILVA, D.J.H. 2005. Cultura da melancia. In: FONTES, P.C.R. (Ed.) Olericultura: teoria e prática. Viçosa, p. 385-406.
RODRIGUES DE MIRANDA, F.; MONTENEGRO, A.A.T.; OLIVEIRA, J.J.G. 2005. Produtividade da melancia irrigada por gotejamento em diferentes espaçamentos de plantio. Revista Ciência Agronômica, Fortaleza, v.36, n.2, p.158 162.

OLIVEIRA, R.P.; SCIVITTARO, W.B.; VASCONCELLOS, L.A.B.C. 1993. Avaliação de mudas de maracujazeiro em função do substrato e do tipo de bandeja. Scientia Agrícola, Piracicaba, v.50, p. 261266.

REZENDE, G.M.; COSTA, N.D.; DIAS, R.C.S. 2010. Sistema de produção de melancia. Embrapa semiárido. On-line. Disponível em: $<$ http://sistemasdeproducao.cnptia.embrapa. br/FontesHTML/Melancia/SistemaProducao Melancia/plantio.htm $>$ Acesso em: $13 \mathrm{de}$ Jul. 2013.

RODRIGUES, E.T.; LEAL, P.A.M.; COSTA, E.; PAULA, T.S.; GOMES, V.A. 2010. Produção de mudas de tomateiro em diferentes substratos e recipientes em ambiente protegido. Horticultura Brasileira, Brasília, v. 28, p. 483-488.

SALVADOR, E. D.; PAQUAL, M.; SPERA, M. R. N. 2001. Efeito de diferente substratos no crescimento de samambaia matogrossensis (Polypodium aureum L.). Ciência Agrotécnica, Lavras, v.25, n.4, p.1006-1011.

SANTINO, S.J.; GADUM, J.; CARDOSO, A.I.I. 2004. Produção de pepino em função da idade das mudas produzidas em recipientes com diferentes volumes de substrato. Horticultura Brasileira, Brasília, v.22, n.3, p.610-613.

SILVA, A.C.R.; FERNANDES, H.S.; MARTINS, S.R.; SILVA, J.B.; SCHIEDECK, G.; ARMAS, E. 2000. Produção de mudas de alface com vermicompostos em diferentes tipos de 
bandeja. Horticultura Brasileira, Brasília, v.18, p.512-513.

SILVA， A.C.R.; FERNANDES， H.S.; HOPPE, M.; MORAES, R.M.D.; PEREIRA, R.P.; JACOB JÚNIOR, E.A. 2000. Produção de mudas de brócolis com vermicompostos em diferentes tipos de bandeja. Horticultura Brasileira, Brasília, v.18, p.514-515.

TAVEIRA, J.A.M. 1995. Produção de mudas. Curitiba: SENAR. $84 p$.

Recebido em: $17 \backslash 11 \backslash 2014$

Aceito para publicação em:24\3\2016 